\title{
Comunicação e interdição: a censura moral sobre o corpo e a palavra
}

\author{
Mayra Rodrigues Gomes / Ferdinando Martins
}

\section{Resumo:}

Este trabalho apresenta resultados obtidos com as pesquisas desenvolvidas pelo Projeto Temático «A cena paulista: um estudo da produção cultural de São Paulo, de 1930 a 1970 a partir do Arquivo Miroel Silveira», iniciado em 2005 com financiamento da Fapesp. O Projeto, que pode ser visualizado em www.eca.usp.br/censuraemcena, é responsável por conservar e estudar mais de 6 mil processos de censura prévia ao teatro. Neste texto, comparecem observações sobre os temas privilegiados pela ação do censor, assim como levantamentos quantitativos das incidências e o exame de alguns casos.

\section{Palavras Chave:}

censura; teatro; comunicação.

\begin{abstract}
:
This work presents the results we have obtained in the researches developed by the Thematic Project «The Paulista scene: a study of cultural production in São Paulo, from 1930 to 1970 from the Miroel Silveira Archive», started in 2005 financed by Fapesp. The Project, that can be visualized in the website www.eca.usp.br/censuraemcena, is responsible for conserving and studying about 6 thousands censorship processes previous to the theater. In this text, we have done some observations around the privileged themes under the censor action, as well as quantitative surveys of the incidences and the examination of some cases.
\end{abstract}

\section{Keywords:}

censorship, theater, communication

\section{Da censura moral}

O Projeto Temático “A cena paulista: um estudo da produção cultural de São Paulo de 1930 a 1970 a partir do Arquivo Miroel Silveira”(1), compreende vários focos de estudos ou pesquisas em desenvolvimento, além da conservação e organização de acervo composto por mais de 6 mil processos de censura teatral.

Trazemos neste artigo alguns resultados e reflexões relacionadas ao estudo das palavras que foram censuradas, tomando-as de um ponto de vista a partir das formações discursivas, enquanto instâncias organizadoras dos grupos sociais.

Consideramos que um discurso se desenha como dispositivo disciplinar. Trata-se, com os dispositivos disciplinares, de educar, conformando os indivíduos, procurando torná-los funcionais em relação a um tipo, ou outro, de organização social, a um tipo, ou outro, de materialização das relações de poder. Para tanto, os procedimentos disciplinares têm a interdição, ou a censura, objeto de nossos estudos, como tática privilegiada, uma vez que: 
(...) em toda sociedade a produção do discurso é ao mesmo tempo controlada, selecionada, organizada e redistribuída por certo número de procedimentos que têm por função conjurar seus poder e perigos, dominar seu acontecimento aleatório, esquivar sua pesada e temível materialidade (FOUCAULT, 1996, p. 8/9).

Podemos pensar, então, que a censura é a manifestação de uma interferência nos discursos, buscando efeitos de poder, que as palavras censuradas são as manifestações de uma relação de poder que atinge os discursos e, ao mesmo tempo, o modo de emergência dos discursos do poder constituído.

Tendo em mente estas considerações, adotamos, em nossa pesquisa sobre palavras censuradas e sobre os temas a que elas remetem, uma classificação já aplicada em estudos anteriormente desenvolvidos junto ao Arquivo Miroel Silveira. Estes estabeleceram quatro campos temáticos de incidência da censura:

1. Censura de ordem moral, pela qual se entende a proibição de palavrões, de termos relacionados a sexo e erotismo..., enfim, nos próprios dizeres dos censores e dos órgãos de censura, de palavras que firam os bons costumes.

2. Censura de ordem política, sob a qual se abrigam as proibições de expressões que possam implicar crítica ao governo, à Nação e a suas relações internacionais.

3. Censura de ordem religiosa, compreendendo a proibição de termos críticos ou ofensivos a uma igreja, assim como a seus santos e representantes temporais.

4. Censura de ordem social, sob a qual se enquadra a proibição de alusão "a questões sociais polêmicas como racismo, preconceito étnico e xenofobia".

Esta divisão em quatro categorias básicas consolida o levantamento quantitativo que empreendemos quanto aos focos de atenção dos censores. Ela é acompanhada de outro procedimento metodológico em relação ao corpus de análise.

Quanto ao conjunto das peças parcialmente liberadas, aquelas que têm palavras ou trechos censurados, determinou-se uma seleção a partir da catalogação já realizada que apontava peças de destaque pelo número de apresentações, pela proeminência do autor, enfim, por sua notoriedade; a outra seleção foi estabelecida por sorteio, em que a aleatoriedade foi tomada como instrumento de garantia de distância, por parte do pesquisador, na constituição do corpus.

Em sua arquitetura final, o corpus dos levantamentos temáticos atravessa os 43 anos do Arquivo e se compõe de 2 peças por ano totalizando 85 peças, porque em 1925, 1939 e 1940 há somente 1 peça, por cada ano, parcialmente liberada. Deste universo, quando aplicada a divisão em quatro categorias, pudemos obter um bom panorama de como a censura agiu e dos seus focos de atenção. 


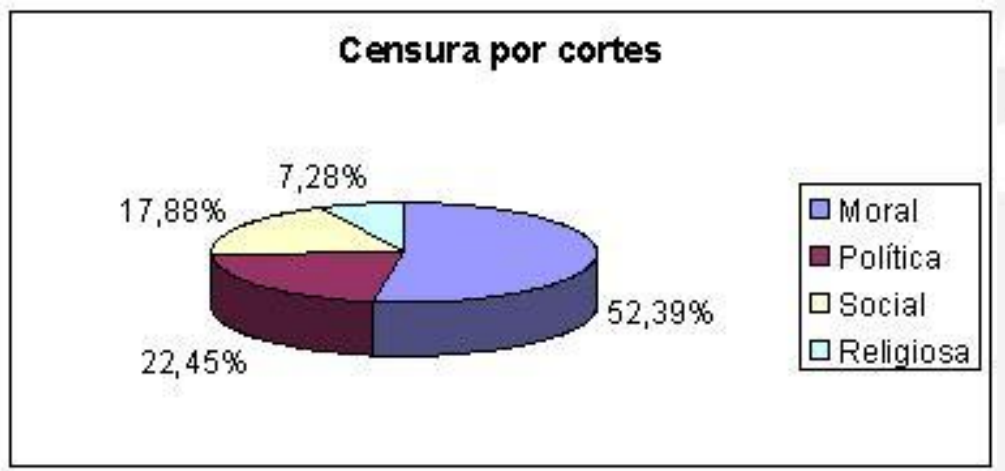

Pela forma de contagem dos cortes, em que cada veto foi considerado isoladamente, chegamos à conclusão de que a maior preocupação censória se insere no campo da moral: aproximadamente $52 \%$ dos cortes versam sobre temas desta ordem. Seguida pelo campo político com um total de $23 \%$ dos cortes. Os temas de ordem social e religiosa aparecem, respectivamente, em $18 \%$ e $7 \%$ dos cortes.

Esses dados iniciais foram explorados em perspectiva diacrônica, o que nos permitiu traçar um gráfico da evolução de cada tipo de censura ao longo das décadas percorridas ano a ano.

Das principais variações apresentadas, destaca-se uma queda nos índices de censura moral de 79,3\%, na década de 20 , para $35,6 \%$ e $36,6 \%$, nas décadas de 40 e 50, subindo levemente para 43,5\%, na década de 60 . Esses números revelam que alterações sociais estavam em curso, sobretudo no que diz respeito à função social de cada agente familiar, bem como a participação do Estado sobre o comportamento destes agentes.

Observamos, também, que a partir da década de 30, o índice de censura social aumentou em relação à primeira década analisada. Podemos associar esta condição ao fato de que o Estado tomou para si a função de apaziguar relações conflituosas entre os diversos grupos e classes sociais, fossem eles étnicos ou econômicos, da mesma forma que buscou manter a integridade de marcas e nomes referentes à esfera privada. Isto porque o regime que se instaura após o golpe de 1930 inaugura a era Vargas, em que se adotam os valores da família, da pátria e do trabalho como pilares discursivos e estratégicos na busca de uma sociedade unificada.

Para prosseguirmos na análise da variação dos tipos de censura ao longo das décadas, introduzimos um terceiro fator, além das modificações na família e no Estado. Trata-se da transformação no teatro brasileiro, que passou a explorar novas vertentes cômicas e dramáticas.

Como foi anteriormente mencionado, adotaram-se dois recortes: uma seleção, ano a ano, foi realizada a partir das peças mais significativas, assinaladas como tal pelo título, autor e importância na cena teatral. Outra seleção foi construída por sorteio, recorrendo à aleatoriedade que imprime isenção. Notou-se, no cômputo geral, uma significativa diferença entre os números obtidos a partir do recorte focado nas peças mais importantes e aquele pautado por um sorteio.

Ambas as seleções obtiveram um maior número de cortes relacionados à moralidade. No entanto, a presença de motivação moral atinge quase o dobro de incidência na seleção por sorteio (67,69\%), em comparação com o recorte das peças mais significativas $(38,49 \%)$. Ao mesmo tempo, ocorre o inverso nas categorias de veto social e político: os índices de cortes de fundo social são de $10,48 \%$ na seleção por sorteio e $24,6 \%$ na seleção de peças significativas, e os de fundo político são respectivamente $14,41 \%$ e $29,76 \%$. As incidências de interditos por motivos religiosos mantêm-se quase iguais em ambas as seleções, a saber, em torno dos $7 \%$. Em suma, percebe-se no recorte de peças mais significativas um maior equilíbrio entre o número de cortes 
enquadrados em cada um dos quatro motivos gerais.

Das 84 peças em questão, a seleção por sorteio é composta por 23 comédias, 15 revistas e 6 dramas. Na outra seleção foram estudadas 21 comédias, 9 dramas, 9 revistas e uma peça infantil, todas de importância reconhecida.

No arquivo, de uma maneira geral, existem 1.036 peças sob o registro de gênero «Teatro de revista» e 2.837 registros do gênero «Comédia». Somadas, as duas categorias formam um conjunto de 3.873 peças que superam a metade do total de registros. Isto significa que estes gêneros perfazem uma maioria dentre as peças presentes no arquivo e catalogadas.

Diante disso, podemos dizer que a maior incidência de revistas entre as peças sorteadas reflete uma tendência na distribuição dos gêneros no acervo, enquanto a seleção das peças mais significativas segue um cânone da história do teatro, que valoriza principalmente a produção dramática vinculada a movimentos de vanguarda e ruptura, por isso a maior incidência de dramas.

Qual o efeito dessa constatação nos resultados obtidos? É possível afirmar que grande parte da produção teatral brasileira se desenvolveu em torno das questões familiares e sexuais, freqüentemente abordadas em sua nuança cômica. As comédias "popularescas", como as revistas, tendem a abordar mais intensamente, ou vulgarmente, os costumes e o sexo, até como forma de atrair público.

De um total de 580 cortes, os campeões de vetos pela censura foram os temas que versam sobre o "ato sexual" em si. Eles correspondem a um total de 70 cortes, ou seja, $12 \%$ dos cortes gerais e $20 \%$ dos cortes no campo da moral.

O "uso de vocabulário impróprio" é o segundo assunto com maior incidência de cortes. Em um total de 44 intervenções - o correspondente a aproximadamente $8 \%$ dos cortes gerais e $13 \%$ dos inseridos dentro do campo da moral - limpar os palavrões e a linguagem obscena foi também uma forma encontrada pelos governos republicanos de moldar o tipo de homem e de sociedade considerados ideais para o país.

O "adultério" é o terceiro tema mais vetado. Ele corresponde a $6 \%$ dos cortes gerais e a $10 \%$ dos cortes morais, num total de 33 intervenções. Ainda dentro desta categoria, podemos notar que há uma incidência de cortes muito maior sobre o adultério feminino. Enquanto este corresponde a 21 intervenções ( $4 \%$ dos cortes gerais e $6 \%$ dos morais), o adultério masculino possui 12 ( $2 \%$ dos gerais e $3 \%$ dos morais).

Com números empatados com os do adultério, a "homossexualidade" também foi um tema bastante vetado. Os cortes aos temas homossexuais continham uma particularidade interessante: ele só era vetado quando o tema era tratado de forma diferente ao aceito na época: como vício ou doença a serem saneados.

Vetos dirigidos diretamente ao "corpo" representam o quarto assunto mais censurado dentro de nosso corpus. As 29 intervenções correspondem a 5\% dos cortes gerais e a 8,5\% dos cortes morais. Enquanto apenas 6 destas intervenções são direcionadas para partes do corpo em geral(2), 23 delas são destinadas especificamente para os órgãos sexuais, o que corresponde a $4 \%$ do total de cortes e a $6,7 \%$ dos cortes morais.

Embora observações anteriores dos trabalhos com o Arquivo Miroel Silveira, sobretudo no decurso do processo de catalogação, já indicassem a prevalência da censura de caráter moral presumida pela sistemática proibição do termo "amante", não esperávamos os resultados obtidos por um olhar mais atento. Supúnhamos até, levando em conta os dois regimes autoritários, cenários dos processos de censura situados entre 1925 e 1968, que a maior incidência recaísse sobre a classificação em censura de caráter político. No entanto, no olho 
do furacão das tensões sociais, nossos estudos mostraram outro foco privilegiado.

Ora, diante do achado de uma insistência da censura sobre temáticas de ordem moral, com seus contornos na sexualidade, devemos formular uma pergunta que antecede qualquer outra e, evidentemente, interroga sobre as razões da preponderância da incidência detectada.

Tal questão é bastante aparentada àquela formulada na obra «História da sexualidade», de Michel Foucault: por que o corpo e a sexualidade têm sido, através dos tempos, o ponto principal da instalação de uma regulagem, da aplicação de dispositivos disciplinares? Também nossa resposta, descontados os campos de saber considerados, é semelhante à que foi dada nos trabalhos do autor.

Há dois caminhos, complementares, pelos quais podemos responder. Abordaremos aqui o que apresenta uma disposição genética quanto ao assunto. Trata-se do fato de que o corpo, em sua assunção primeira por uma criança, como totalidade, torna-se o ponto de fixação das coordenadas que a orientarão em sua construção de identidade, que implica sua subjetividade.

Dentre desse vetor, a coordenada mais proeminente será a da sexualidade, determinada pelo cruzamento entre características biológicas e identificações assumidas. Portanto, compreende-se como natural o fato de que corpo e sexualidade sejam privilegiados pela censura, já que constituem o lócus de assentamento das identidades, as sociais inclusivas, lócus das disputas e das problematizações fundamentais sobre quem somos, como devemos ser e que sentido nos anima.

Nesse ponto, confrontamos o cerne do mecanismo que preside qualquer tomada disciplinar e, portanto, qualquer ato de censura. Não há como mostrar uma qualificação sem mostrar a desqualificação, não há como mostrar o bom uso dos prazeres sem delinear sua contrapartida. Em outros termos, não há como fundar uma moral no corpo e na sexualidade sem que mostremos sua face inversa.

Entende-se, assim, que as formações discursivas, dispostas na exclusão efetuada pelos censores, como já apontamos, recaiam majoritariamente sobre os usos dos prazeres, ou a temática de «ordem moral», focada na sexualidade, ou modos de assunção do corpo, conforme a denominamos neste estudo. Estas assunções determinam os modos de ser socialmente, as posições de sujeito a serem vividas, posições cuja ordenação é sempre de interesse para o controle do quadro social.

Por outro lado, não devemos esquecer que as subjetividades não são simplesmente um anteparo sobreposto aos corpos. São, antes de mais nada, a determinação e a manifestação das formas com que se vivenciará o corpo. É de se supor que a reiteração das intervenções do censor também chegue à forma capilar de manifestação do poder, mencionada por Foucault, forma mais interferente, por ter a propriedade de atravessar e moldar os corpos.

\section{Corpo e censura}

Durante o século XX, foram observadas em todo o mundo alterações sociais, políticas, econômicas e comportamentais. Novas formas de ver, ouvir e sentir emergiram com as vanguardas do início do século XX e romperam sobremaneira a tradição das práticas artísticas, em revoluções tão profundas quanto aquelas do Renascimento. No teatro, essas mudanças refletem-se, sobretudo no novo estatuto do corpo em cena. 
Como vimos, o corpo é um dos temas privilegiados pela censura. Sua exposição e movimentação são vigiadas e os termos que lhe referem são controlados. Isso fica claro, por exemplo, no processo da comédia «A Lógica da Poligamia», de André Roussin.

Em 1952, o grupo Aimée e sua Moderna Companhia de Comédia solicita a censura da peça a fim de encenála no pequeno auditório do Teatro Cultura Artística. A trama é ousada. Um casal de náufragos divide espaço em uma ilha com o amante da mulher, que lá se envolve com um terceiro homem, o cozinheiro do navio. Trata-se de uma comédia apimentada, mas para preservar o que chama de decoro, o censor Benedito Geraldo da Rocha Corrêa faz vetos em 28 páginas (o total do texto era de 86 páginas). Em relação ao corpo, vários dos cortes referiam-se a sua exposição ("semi-nua", "nua", "toda nua") a sua movimentação ("esfregando", "estendida"). Os trechos abaixo, retirados respectivamente das páginas 6, 43, 52 e 81, contextualizam essas expressões. Destacamos em negrito as palavras vetadas.

Henrique: Estou farto de te ver semi-nua o dia inteiro e só ter o direito de beijar a tua mão à noite, quando Felipe e tu entram... ali (mostra a cabana à direita).

Henrique: É admirável.

Suzana: O quê?

Henrique: Chegar como um imbecil e encontrar vocês se esfregando daquela forma. [...] Beijamonos, e que não tem nada a ver com a grosseria que acabas de pronunciar. [...]

Henrique: ... Digo que acho isso desagradável e não há nenhuma exageração nisso uma única vez, na semana passada. Felipe não teve ocasião de nos encontrar assim, mantive sempre uma discrição que ele não mantém. É a terceira vez, em quatro dias, que encontro vocês assim, beijando-se vergonhosamente ou então tenho que me afastar porque me sinto demais.

Felipe: Mas... me impor o quê?

Henrique: O sofrimento de imaginar tua mulher nos meus braços.

Henrique: ... A mim, cada pedaço teria ficado entupido na garganta porque esse peixe teria sido para mim um drama...o drama de Suzana estendida na cabana com o negro.

Nota-se que há uma dupla moral, uma vez que o adultério é uma situação explícita na peça, mas os vetos recaem sobre as insinuações que indicavam o relacionamento sexual entre os personagens. A censura, porém, atém-se somente às palavras. É esse também o caso, entre outros, do processo da peça «O Anjo de Pedra», de Tennesse Williams, solicitado pelo TBC em 1950. O único trecho vetado está na página 70:

Rosa: De noite eu tinha que ouvir tudo que meu pai e minha mãe faziam. Ele grunhia como um porco em cima dela, para mostrar sua paixão. E eu pensava comigo mesma como é sujo fazer amor e como é sujo ser mexicano e ter de dormir todos num só quarto de chão imundo, cheirando mal porque não havia nem bacia.

Em outras situações, os vetos podem se estender também à encenação ou à interpretação. O dramaturgo e 
roteirista Max Nunes, em entrevista para o projeto temático, recorda uma situação peculiar:

Na revista «O mundo é das mulheres», de Jorge Maia, havia um quadro meu em que as mulheres apareciam com os seios de fora. o censor não gostou, mas não proibiu totalmente. Deixou as mulheres lá, só que elas não poderiam se mexer com os seios de fora. Acho que era para não balançar.

Esse tipo de veto era possível especialmente quando o censor assistia aos ensaios. No processo de «O Rei da Vela», peça de Oswald de Andrade montada pela primeira vez em 1967 pelo Teatro Oficina, o censor chama a atenção para "certos gestos físicos" dos atores, em especial "segurar e levantar o pênis por cima da calça, à imitação de sorvete caracterizando um pênis".

Também é importante ressaltar que a censura que relaciona o corpo à sexualidade é aparentemente a mais recorrente, mas não é exclusiva. Em alguns casos, o corpo pode ser censurado por remeter a sua fisiologia (o que feria os estandartes do bom gosto), ou por caracterizar situação acintosa para as autoridades.

Em todos os casos, porém, mais do que refletir o contexto histórico ou confirmar certas concepções, a censura reforça o poder comunicativo do corpo. Ao vetar sua expressão, assume que há um código baseado em gestos, posturas e exposições do corpo. Isso vai ao encontro de uma das mudanças mais profundas nas práticas teatrais do século XX: a codificação do corpo.

Muitas foram as mudanças na prática teatral nos últimos dois séculos. Mas foi no corpo, em sua comunicação e em sua política, que as maiores mudanças podem ser identificadas. Isso porque, até o século XIX, a representação teatral era, sobretudo, leitura de textos, o que conferia às artes dramáticas um espaço privilegiado na Teoria Literária e na História da Literatura. Segundo Lehmann,

Antes da modernidade a realidade física do corpo permaneceu geralmente incidental no teatro. Disciplinado, treinado e moldado para a função da significação, o corpo não era nem um problema nem um tema autônomo do teatro dramático, no qual permaneceu sobretudo como uma espécie de "subentendido". Isso não é de surpreender, já que o drama se constitui essencialmente em função da abstração da densidade do material, da concentração "dramática" em conflitos espirituais - em contraposição à predileção épica pelo detalhe concreto. Assim, a sexualidade aparece como amor; a dor e a degeneração como sofrimento e morte (LEHMANN, 2007, p.. 332).

Não por acaso, a figura do ponto ou «suflair» que ditava as falas dos personagens aos atores só desapareceu há poucas décadas. A centralidade do texto no teatro já era questionada pelo enciclopedista Denis Diderot. Dorval, «alter ego» de Diderot na peça «O filho natural», afirmava:

Falamos demais em nossos dramas, e, conseqüentemente, nossos atores não desempenham muito. Perdemos uma arte, cujos recursos os antigos conheciam bem. A pantomima desempenhava outrora todas as condições, os reis, os heróis, os tiranos, os ricos, os pobres, os habitantes das cidades, aqueles do campo, escolhendo em cada estado o que lhe é próprio; em cada ação, o que ela tem de marcante (SZONDI, 2004, p. 107)

Também no «Discurso sobre a poesia dramática», Diderot critica a falta de movimentação: "Da minha parte, não concebo como o poeta pode começar uma cena, se não imaginar a ação e o movimento do personagem que introduz; e se o andar e o rosto dele não lhe estiverem presentes" (DIDEROT, 2005, pp. 94-5). 
Porém, será ao longo do século XX, concomitante ao desenvolvimento de novas tecnologias de comunicação e novos recursos cênicos, em especial a iluminação, que outras linguagens além da literária ganham espaço na representação. Há que se pensar, portanto, a influência dos meios de comunicação de massa sobre esse novo estatuto para o corpo em que o cinema desempenhou papel determinante. Por isso, já na década de 1930, Antonin Artaud afirmava:

Nós estamos, agora, no estádio de vida aplicada, onde tudo desapareceu, natureza, magia, imagens, forças; no estado de estagnação em que o homem vive de seu dote, com uma reserva sentimental e moral há um século imutável. Neste estádio o teatro não cria mais mitos. Os mitos mecânicos da vida moderna foi o cinema que os assumiu (ARTAUD, 1995, p. 76).

Denis Guénoun, seis décadas depois de Artaud, conclui que, de fato, o cinema ocupou o espaço do teatro na produção da catarse e, por isso, novas funções passam a ser atribuídas às artes dramáticas.

Desde que os heróis se refugiaram nas imagens, não se vai mais ao teatro para desfrutar de personagens ou de situações. $\mathrm{O}$ que não acarreta que a pessoa se queixe quando isto acontece: podem ser suplementos benvindos. Mas é para o cinema, não para o teatro, que nos leva a procura de gratificações situacionais, dramáticas, identificatórias. Ninguém vai mais ao teatro na esperança de ali se deixar envolver, enfeitiçar, iludir pelos prestígios oníricos ou fantasmáticos de uma narrativa ou de uma figura. Os espectadores que buscam histórias entram num cinema ou ligam o videocassete. [...] Vai-se ao teatro para ver um espetáculo, de acordo com a expressão hoje em dia familiar. O que isso quer dizer? Precisamente o seguinte: que a pessoa vai ao teatro com a intenção de que ali lhe apresentem uma operação de teatralização (GUÉNOUM, 2004, p. 139).

No cinema, o corpo é ampliado, recortado, multiplicado, manipulado. Com isso, os atores que passaram a trafegar entre os dois meios, incorporaram novas dinâmicas calcadas no corpo para seu trabalho de representação. Segundo Jorge Hacker:

Los creadores del teatro aportaron su intuición sobre El significado de la imagen em acción, abrieron las puerta de los estrechos interiores victorianos y se entregaron al vértigo. Los actores descubrieron los primeros planos, la multiplicación de sus rostros al infinito, El estrellato.(HACKER, 1995, p. 327)

É nesse contexto que o corpo, outrora relegado, passa a se constituir como linguagem no âmbito das artes dramáticas, e, desde então, a codificação de gestos e movimentos corporais passam a ser determinantes nos espetáculos. Conforme afirma Terry Eagleton sobre o corpo nas artes do século XX é "um assunto tão óbvio e importuno a ponto de ter sido brandamente omitido por séculos - tem atingido as fronteiras de um discurso frio e racionalista, e está em vias de se tornar o maior fetiche de todos" (EAGLETON, 1996, p. 25). Não é por acaso, portanto, que o corpo, ausente nas reflexões do passado, ganha espaço nas obras dos teóricos do teatro. Constantin Stanislavski, uma das principais referências na área de interpretação dramática no século XX, assim se refere ao corpo em cena: “[...] representando, nenhum gesto deve ser feito apenas em função do próprio gesto. Seus movimentos devem ter sempre um propósito e estar sempre relacionados com o conteúdo de seu papel” (STANISLAVSKI, 1989, p. 68.).

No teatro épico de Bertold Brecht, cabe ao corpo do ator produzir o efeito de distanciamento, traço que singulariza essa proposta estética.

[...] é necessário que digamos desde já que tudo o que seja sentimento deve ser exteriorizado (em 
outras palavras: tornar-se gesto). [...] O teatro chinês revela um grande domínio da arte do gesto. E é dessa forma que o ator chinês consegue obter o efeito de distanciamento: vemo-lo observar os próprios gestos (BRECHT, 1967, p. 89).

Opondo-se ao simbolismo da virada do século XIX para o XX, que sobrevalorizava o texto dramático em detrimento de sua representação, Antonin Artaud afirma na década de 1930 que o teatro é o lugar onde se refaz o corpo. O corpo refeito e reorganizado artaudiano deve libertar-se de automatismos, corpo-sem-órgãos que servirá de base para a filosofia de Gilles Deleuze e Félix Guattari (DELEUZE \& GUATTARI, 1996). Em larga medida, teóricos do teatro como Jerzy Grotowski e Vsévolod Meyerhold irão igualmente tratar desse novo estatuto do corpo. Segundo Patrice Pavis:

O corpo do ator situa-se, no leque dos estilos de atuação, entre a espontaneidade e o controle absoluto, entre um corpo natural ou espontâneo e um corpo-marionete, inteiramente preso a cordéis ou manipulado por seu sujeito ou pai espiritual: o encenador (PAVIS, 1999, p. 75).

Para esse teórico do teatro, depois de "liberados da tarefa textual", os encenadores buscaram definir uma linguagem corporal.

Na década de 1960, mudanças mais evidentes, decorrentes de processos engendrados anteriormente, ampliaram ainda mais o impacto da comunicabilidade do corpo. A vivência mais livre da sexualidade, a maior presença da mulher no mercado de trabalho, a emergência de novos movimentos sociais e o uso de drogas recreativas relacionam-se com um novo estatuto e uma nova política para o corpo.

Estruturando-se como linguagem, gestos e movimentos corporais passam também a ser objetos de censura e controle. A lógica da censura coaduna-se com a lógica de controle imposta pela modernidade, pela qual até mesmo os corpos são catalogados e explicados pelas regras de normatização. Segundo Foucault, o discurso sobre a sexualidade, por exemplo, revela que não há liberdade, até mesmo porque há um discurso, o que implica uma organização de campo, e porque há um discurso como ciência do sexo a ditar os padrões. $\mathrm{O}$ discurso médico, por sua vez, impõe um escrutínio do corpo que leva à fundação de padrões para o uso do corpo, em nome da higiene, da saúde e da longevidade.

Mais ainda, os corpos são também sujeitos a olhares. Na modernidade, há um processo de racionalização crescente, alicerçado no discurso da ciência; um processo de vigilância, onde os corpos são obrigados a se conduzirem em função do que é estabelecido como normal sob pena de exclusão para os desviantes.

Essa racionalização atinge a atividade dos censores da Divisão de Diversões Públicas, mas não de maneira homogênea. Verifica-se que os padrões da censura ao corpo são influenciados pelo momento histórico, orientações políticas, sociais e culturais, e pelo personalismo da atividade, que relega ao censor um poder que, em larga medida, servirá para a manifestação de opiniões e pontos de vista pessoais. Dessa forma, "somos obrigados a entender que a censura feita de maneira rotineira, burocrática e, na maioria das vezes, consensual e sendo superficial em suas conseqüências, torna-se a expressão dos mais variados preconceitos e conflitos" (COSTA, 2006, p. 18). Por isso, segundo Cristina Costa, "o estudo da censura não deve se limitar à crítica ao abuso do poder e à defesa da liberdade de expressão, mas deve também passar pela compreensão do papel que ela desempenha no exercício de uma política cultural" (COSTA, 2006, p. 16).

O corpo, sua erotização e política são objetos recorrentes de vetos da censura. Percebe-se, assim, que as mudanças ocorridas ao longo do século XX incidem diretamente sobre a prática dos censores. Companhias teatrais e censores trilharam caminhos inversos em relação a essas mudanças - os primeiros, rumo a uma 
suposta maior liberdade sexual, os segundos em direção a uma manutenção dos valores tradicionais de decoro. Na década de 1960, o Teatro de Arena e o Teatro Oficina parecem ter radicalizado ainda mais a defesa da liberdade do corpo, o que, relativamente, coloca o TBC em uma posição conservadora - ainda que distante da dos censores.

Levando-se em conta que, após 1964, o Brasil viveu um período de intensificação da censura, decorrente da militarização do Estado, acreditamos que a situação política tenha incidido sobre a prática dos censores e afetado a produção teatral em relação à censura do corpo e sua comunicação.

A fricção de forças entre a política conservadora e a política libertária do corpo, que pode ser vista nos processos do Arquivo Miroel Silveira, torna-se mais acirrada em períodos de autoritarismo. Entretanto, por sua natureza, a contenção do corpo se desdobra, ainda que não seja objeto explicito de censura, como forma de retenção dos fluxos que movem as cenas da vida.

\section{Bibliografia:}

ARTAUD, Antonin. Linguagem e vida. São Paulo: Perspectiva, 1995.

BRECHT, Bertold. "Função social do teatro". Em: VELHO, Gilberto (org.). Sociologia da Arte, III. Rio de Janeiro: Zahar, 1967.

COSTA, Maria Cristina Castilho. Censura em Cena - o teatro e a censura no Brasil, a partir do Arquivo Miroel Silveira. São Paulo: Edusp \& Imprensa Oficial, 2006.

DELEUZE, Gilles e GUATTARI, Felix. Mil platôs. Capitalismo e esquizofrenia. Vol. 1. Rio de Janeiro: 34, 1995.

. Mil platôs. Capitalismo e Esquizofrenia. Vol 3. São Paulo: Ed. 34, 1996.

DIDEROT, Denis. Discurso sobre a poesia dramática. São Paulo: Cosac Naify, 2005.

FOUCAULT, Michel. A ordem do discurso. São Paulo: Loyola, 1996.

. História da sexualidade. Vol. I A vontade de saber. Rio de Janeiro: Graal, 1997.

. Microfisica do poder. Rio de Janeiro: Graal, 2001.

. Vigiar e punir: História da violência nas prisões. Petrópolis: Vozes, 1988.

GUÉNOUN, Denis. O teatro é necessário? São Paulo: Perspectiva, 2004.

HACKER, Jorge. “El cine: arte dramatico". In: PELLETTIERI, Osvaldo (org.). El teatro y los días. Estúdios sobre teatro iberoamericano y argentino. Buenos Aires: Galerma, 1995.

LEHMANN, Hans-Thies.Teatro pós-dramático. São Paulo: Cosac Naify, 2007.

PAVIS, Patrice. Dicionário de teatro. São Paulo: Perspectiva, 1999.

STANISLAVSKI, Constantin. A construção da personagem. Rio de Janeiro: Civilização Brasileira, 1989. 
SZONDI, Peter. Teoria do drama burguês. São Paulo: Cosac Naify, 2004.

\section{Notas:}

Mesa apresentada no III Colóquio Multitemáticos em Comunicação - Multicom, evento componente do XXXI Congresso Brasileiro de Ciências da Comunicação.

(1) O Projeto, desenvolvido na ECA-USP, é coordenado pela profa. dra. Maria Cristina Castilho Costa, com apoio da FAPESP.

(2) O que corresponde a $1 \%$ dos cortes totais e $1,75 \%$ dos cortes morais.

\section{Mini Currículo :}

Mayra Rodrigues Gomes: Professora Doutora, Livre Docente, do Departamento de Jornalismo e Editoração da ECA/USP. Pesquisadora de projetos com apoio do CNPq e da FAPESP. Autora, entre outros, dos livros Jornalismo e Ciências da Linguagem, Poder no Jornalismo e Jornalismo e Filosofia da Comunicação.

Ferdinando Martins. Mestre e Doutor em Sociologia pela Faculdade de Filosofia, Letras e Ciências Humanas da Universidade de São Paulo. Pós-doutorando e coordenador de Gestão da Informação do Arquivo Miroel Silveira da Escola de Comunicações e Artes da USP. 